\title{
Acute kidney disease and acute kidney injury biomarkers in coronary care unit patients
}

Yih-Ting Chen ${ }^{1}$, Chang-Chyi Jenq ${ }^{2}$, Cheng-Kai Hsu' ${ }^{1}$, Yi-Ching Yu ${ }^{3}$, Chih-Hsiang Chang ${ }^{2}$, Pei-Chun Fan², Heng-Chih Pan ${ }^{1}$, I-Wen $\mathrm{Wu}^{1,4}$, Wen-Jin Cherng ${ }^{5}$ and Yung-Chang Chen ${ }^{1,4,6,7^{*}}$

\begin{abstract}
Background: Acute kidney disease (AKD) describes acute or subacute damage and/or loss of kidney function for a duration of between 7 and 90 days after exposure to an acute kidney injury (AKI) initiating event. This study investigated the predictive ability of AKI biomarkers in predicting AKD in coronary care unit (CCU) patients.

Methods: A total of 269 (mean age: 64 years; 202 (75\%) men and 67 (25\%) women) patients admitted to the CCU of a tertiary care teaching hospital from November 2009 to September 2014 were enrolled. Information considered necessary to evaluate 31 demographic, clinical and laboratory variables (including AKI biomarkers) was prospectively recorded on the first day of CCU admission for post hoc analysis as predictors of AKD. Blood and urinary samples of the enrolled patients were tested for neutrophil gelatinase-associated lipocalin (NGAL), cystatin C (CysC) and interleukin-18 (IL-18).

Results: The overall hospital mortality rate was 4.8\%. Of the 269 patients, 128 (47.6\%) had AKD. Multivariate logistic regression analysis revealed that age, hemoglobin, ejection fraction and serum IL-18 were independent predictors of AKD. Cumulative survival rates at 5 years of follow-up after hospital discharge differed significantly $(p<0.001)$ between subgroups of patients diagnosed with AKD (stage OA, OC, 1, 2 and 3). The overall 5-year survival rate was 81.8\% (220/269). Multivariate Cox proportional hazard analysis revealed that urine NGAL, body weight and hemoglobin level were independent risk factors for 5-year mortality.

Conclusions: This investigation confirmed that AKI biomarkers can predict AKD in CCU patients. Age, hemoglobin, ejection fraction and serum IL-18 were independently associated with developing AKD in the CCU patients, and urine NGAL, body weight and hemoglobin level could predict 5-year survival in these patients.
\end{abstract}

Keywords: AKD, CCU, AKI, Biomarker and CKD

\footnotetext{
* Correspondence: cyc2356@adm.cgmh.org.tw

'Department of Nephrology, Chang Gung Memorial Hospital, Keelung,

Taiwan

${ }^{4}$ College of Medicine, Chang Gung University, Taoyuan, Taiwan

Full list of author information is available at the end of the article
}

(c) The Author(s). 2020 Open Access This article is licensed under a Creative Commons Attribution 4.0 International License, which permits use, sharing, adaptation, distribution and reproduction in any medium or format, as long as you give appropriate credit to the original author(s) and the source, provide a link to the Creative Commons licence, and indicate if changes were made. The images or other third party material in this article are included in the article's Creative Commons. licence, unless indicated otherwise in a credit line to the material. If material is not included in the article's Creative Commons licence and your intended use is not permitted by statutory regulation or exceeds the permitted use, you will need to obtain permission directly from the copyright holder. To view a copy of this licence, visit http://creativecommons.org/licenses/by/4.0/ The Creative Commons Public Domain Dedication waiver (http://creativecommons.org/publicdomain/zero/1.0/) applies to the data made available in this article, unless otherwise stated in a credit line to the data. 


\section{Background}

Kidney damage lasting between 7 and 90 days after an acute kidney injury (AKI) is termed acute kidney disease (AKD) [1-3]. Although many studies have reported on AKI and chronic kidney disease (CKD), few studies have investigated AKD.

The causes of renal function impairment in patients admitted to a coronary care unit (CCU) are complex and multifactorial [4-7]. Cardio-renal syndrome (CRS) was first proposed by Ronco and colleagues in 2008 [8] in an attempt to clarify the crosstalk between the heart and kidneys. The CRS is defined as a pathophysiologic illness of the heart and kidneys in which acute or chronic dysfunction of one organ may induce acute or chronic dysfunction of the other. There are five categories in the CRS and the first, third and fifth types of CRS are associated with AKI. A recent study conducted in the CCU of Chang Gung Memorial Hospital reported an incidence of AKD of 29\% [9]. The use of AKI biomarkers in the diagnosis and prognosis of AKI in critically ill patients has also been demonstrated [10, 11]. However, the role of AKI biomarkers in the diagnosis of AKD and the impact of AKD on mortality are unclear, and new classification systems for AKD may improve standardization of the diagnosis and staging of this clinical syndrome.

Accordingly, there were two aims in this study. First, to explore the predictors of AKD in CCU patients and identify associations between AKI renal biomarkers and patient prognosis. Second, to analyze the severity of $\mathrm{AKD}$ as a clinical predictor of long-term adverse outcomes.

\section{Methods}

\section{Study design and patient population}

This clinical research was conducted in the CCU of one tertiary care teaching hospital in Taiwan between November 2009 and September 2014. The Institutional Review Board at Chang Gung Memorial Hospital approved the study protocol (approval No. 201702274B0). Patients who exhibited any of the comorbidities associated with AKI and AKD were enrolled in this investigation. The following risk factors were considered to be associated with AKI and AKD: age $>65$ years, diabetes mellitus, congestive heart failure (functional class III or IV), and chronic kidney disease (CKD, defined as an estimated glomerular filtration rate $\leq 60 \mathrm{~mL} / \mathrm{min}$ ). All patients provided written informed consent to join the study. Overall, 319 patients were included initially. Patients aged $\leq 18$ years $(n=2)$, those with end-stage kidney disease $(n=12)$, duration of hospital stay $<7$ days $(n=34)$ and readmission $(n=2)$ were excluded. In total, 269 critically ill patients were enrolled (Fig. 1).

\section{Data collection}

Post hoc analysis of a prospectively collected database was used to examine the following variables during CCU admission: demographic characteristics, primary diagnosis, routine biochemistry tests and serial serum creatinine on day 1, 2, 3 and 7. Serum creatinine levels at the end of first month and third month after CCU admission were collected via record reviews. Levels of interleukin-18 (IL-18), cystatin $\mathrm{C}(\mathrm{Cys} \mathrm{C})$, and neutrophil gelatinase-associated lipocalin (NGAL) on the first day of CCU admission were measured in urine and serum samples from all of the enrolled cases. The primary study endpoint was the diagnosis of AKD in order to determine the predictive value of AKI biomarkers in the diagnosis of AKD. The secondary outcome was 5-year mortality to assess the prognostic value of the biomarkers. After hospital discharge, 5 years of follow-up data were evaluated via medical records or telephone interviews as needed.

\section{Definitions}

Acute myocardial injury was defined according to the Third Universal Definition of Myocardial Infarction, ESC/ACCF/AHA/WHF Expert Consensus Document [12] as: an increase and/or decrease in cardiac biomarkers (we evaluated troponin I in this study) >99th percentile of the upper reference limit, plus one or more of the following: 1. Development of pathological Q waves. 2. Imaging evidence of the new loss of cardiac muscles or new regional wall motion abnormalities. 3 . Symptoms of myocardial ischemia. 4. New left bundle branch block or significant new changes in ST-segment$\mathrm{T}$ wave (ST-T). 5. Intracoronary thrombus. Heart failure was diagnosed according to the Framingham criteria [13], and the American College of Chest Physicians/Society of Critical Care Medicine (ACCP/SCCM) Consensus Conference criteria were used to define respiratory failure and sepsis [14] as the the need for mechanical ventilation and a systemic response to infection, respectively. AKI was defined according to the clinical practice guidelines of the Kidney Disease: Improving Global Outcomes (KDIGO) AKI work group [15] as: an increase in serum creatinine levels of $\geq 0.3 \mathrm{mg} / \mathrm{dL}$ within $48 \mathrm{~h}$; an increase of $\geq 1.5$ times the baseline value within the last 7 days; or urine output $<0.5 \mathrm{~mL} / \mathrm{kg} / \mathrm{h}$ for $6 \mathrm{~h}$. The Chinese Modification of Diet in Renal Disease equation was used to calculate the estimated glomerular filtration rate [16]. The stage of AKD staging was determined using baseline serum creatinine levels, which were measured during the first CCU admission.

AKD and renal recovery were defined according to the consensus report of the Acute Disease Quality Initiative (ADQI) 16 Workgroup and the staging criteria for AKD in San Diego, USA on November 8-10, 2015 [1]. Patients were grouped according to $\mathrm{AKD}$ stage as $\mathrm{OA}, 0 \mathrm{~B}$, 
Overall 319 patients admitted to

CCU between November 2009

and September 2014 met the inclusion criteria.

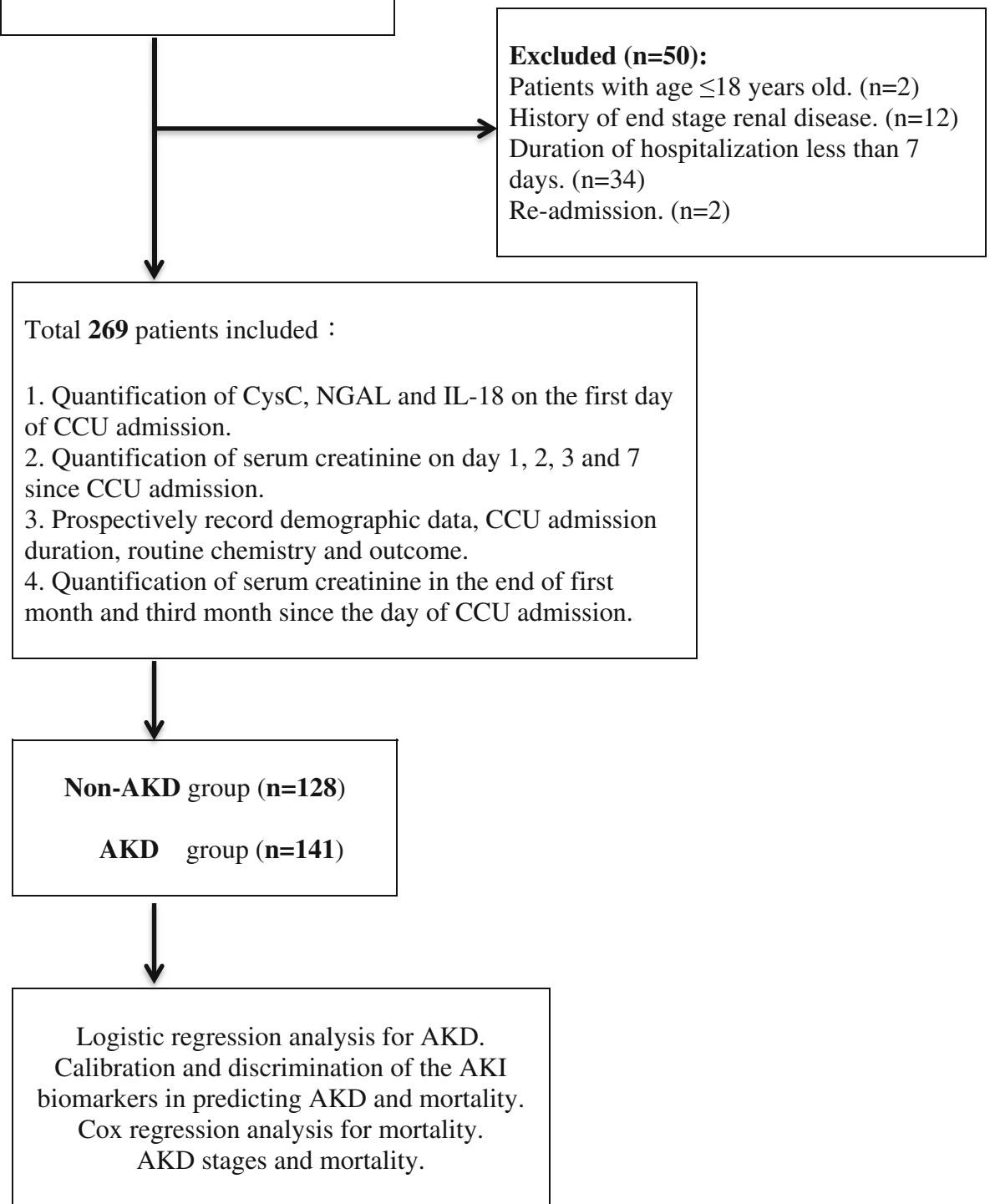

Fig. 1 Study flow chart. AKI, acute kidney injury; AKD, acute kidney disease; CCU, coronary care unit; IL-18, interleukin 18; NGAL, neutrophil gelatinase-associated lipocalin; CysC, cystatin C

0C, 1, 2 and 3. The stages of AKD were defined as follows: stage 0 , patients with incomplete recovery from AKI; stage $0 \mathrm{~A}$, patients without damage markers or structural deficits after an AKI event who are still at risk of long-term events; stage $\mathrm{OB}$, patients with ongoing kidney injury, damage, or loss of renal functional reserve even though the serum creatinine level has returned to baseline levels; stage $0 \mathrm{C}$, patients with a serum creatinine level higher than but within 1.5 times of the baseline level; stage 2, patients with a serum creatinine level 2.02.9 times higher than the baseline level; and stage 3, patients with a serum creatinine level $>3.0$ times higher than baseline or $\geq 4.0 \mathrm{mg} / \mathrm{dl}$, or an ongoing need for renal replacement therapy (Fig. 2). No patient met the criteria for stage $O B$ due to a lack of biomarker data during the follow-up period from day 7 to day 90 .

\section{Sampling and quantifying urinary and serum biomarkers}

Blood and urine samples were collected in sterile nonheparinized tubes immediately after CCU admission, centrifuged at $1500 \mathrm{rpm}$ for $10 \mathrm{~min}$. The samples were then stored at $-80{ }^{\circ} \mathrm{C}$ until further analysis. Levels of 


\section{Injury}

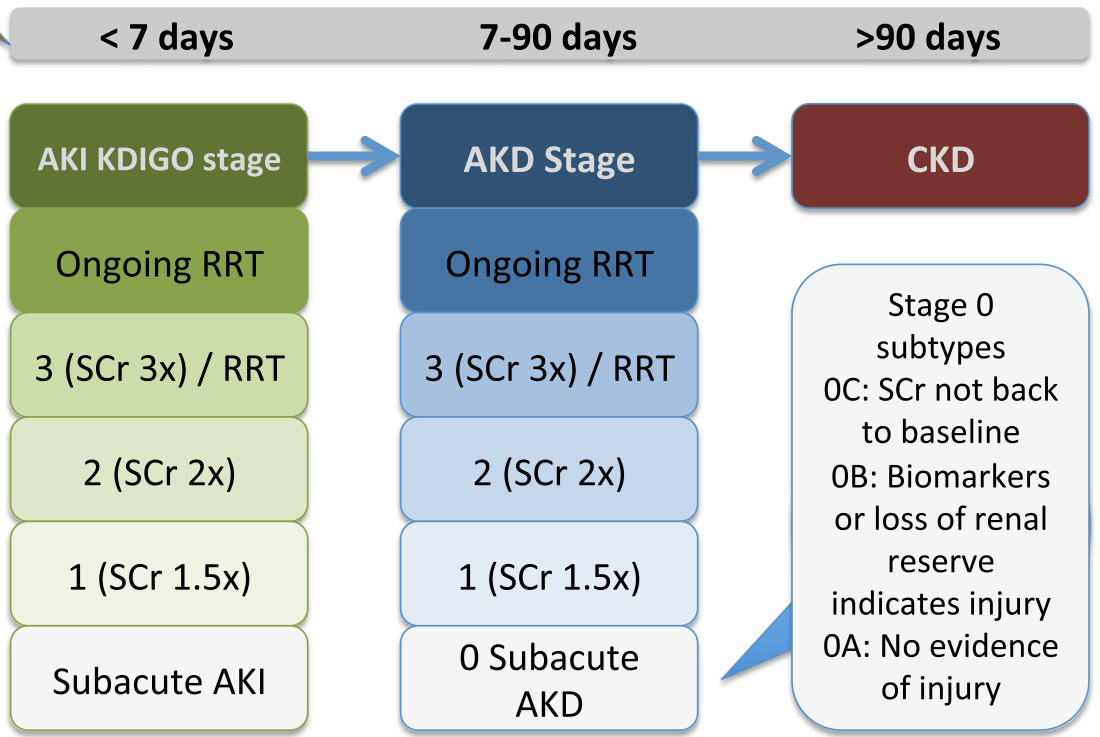

Fig. 2 Acute kidney injury and acute kidney disease stages. AKI, acute kidney injury; AKD, acute kidney disease; CKD, chronic kidney disease; RRT, renal replacement therapy; KDIGO, Kidney Disease Improving Global Outcomes; SCr, serum creatinine

CysC and NGAL in urine and serum were measured in duplicate using a single enzyme-linked immunosorbent assay (R\&D Systems, Minneapolis, MN, USA), and IL-18 levels were measured using another single a single enzyme-linked immunosorbent assay (Medical and Biologic Laboratories, Nagoya, Japan) according to the manufacturers' instructions. Serum levels of B-type natriuretic peptide were measured using a commercial immunoassay, and an autoanalyzer was used to measure levels of high-sensitive $\mathrm{C}$-reactive protein.

\section{Statistical analysis}

Continuous variables are presented as mean \pm standard error unless otherwise stated. The patients with and without AKD were compared in the primary analysis, and the distribution of each variable was evaluated using the KolmogorovSmirnov test. The means of continuous and normally distributed variables were compared using the Student's $t$-test, and the Mann-Whitney $U$ test was used for non-normally distributed variables. The chi-square test or Fisher's exact test was used to compare categorical variables. The chi-square test for trends was used to analyze categorical data associated with the stage of AKD. Univariate analysis was used to identify the predictors of AKD. The statistically significant $(p<$ 0.001 ) variables in the univariate analysis were then entered into multivariate logistic regression analysis using backward stepwise selection. Univariate Cox proportional hazard analysis was used to identify the statistically significant $(p<0.05)$ risk factors for 5 -year mortality. Multivariate Cox analysis was then used with these risk factors to identify the independent predictors of 5-year survival.
The Hosmer-Lemeshow goodness-of-fit test was used to assess calibration of the number of predicted and actual deaths for all probabilities. The area under a receiver operating characteristic curve was used to assess discrimination, and compared using a nonparametric approach.

The Kaplan-Meier method was used to plot cumulative survival curves, which were compared using the log-rank test. All statistical tests were two-tailed, and a $p$ value of $<$ 0.05 was considered to be statistically significant.

\section{Results}

Study population characteristics

Overall, 269 patients (202 men and 67 women) with a mean age of 64 years were investigated. AKD was diagnosed in 128 patients (47.6\%) and 13 patients (4.8\%) died during hospitalization. The patients in the AKD group had a significantly higher incidence of receiving renal replacement therapy during CCU admission $(5.5 \%$ vs. $0.7 \% ; p=0.029)$, a 2.5 -fold higher rate of in-hospital mortality $(7.1 \%$ vs. $2.8 \% ; p=0.154)$, and a higher 5 -year all-cause mortality rate $(22.7 \%$ vs. $14.2 \%$; $p=0.083)$.

\section{AKD and AKI biomarkers}

Table 1 lists the demographic data and clinical characteristics of the AKD and non-AKD groups. The AKD group was older, had a higher incidence rate of sepsis, higher body temperature, and higher respiratory rate than the non-AKD group. In addition, the AKI group had higher levels of AKI biomarkers including serum IL18, NGAL, and CysC, and urine NGAL. There were also 
Table 1 Baseline demographic and clinical data in the patients with and without AKD

\begin{tabular}{|c|c|c|c|c|}
\hline & All Patients $(\boldsymbol{n}=269)$ & $\operatorname{AKD}(\boldsymbol{n}=128)$ & $\begin{array}{l}\text { Non-AKD } \\
(\boldsymbol{n}=141) \\
\end{array}$ & $\boldsymbol{p}$-value \\
\hline \multicolumn{5}{|l|}{ Demographic and clinical variables } \\
\hline Age (years) & $64 \pm 1$ & $68 \pm 1$ & $61 \pm 1$ & $<0.001$ \\
\hline Gender, Male(\%) & $202(75)$ & $97(76)$ & $105(74)$ & NS(0.888) \\
\hline Body weight (kg) & $66.3 \pm 0.8$ & $65.2 \pm 1.1$ & $67.4 \pm 1.0$ & NS(0.157) \\
\hline Diabetes mellitus, $n(\%)$ & $110(41)$ & $58(45)$ & $52(37)$ & NS(0.173) \\
\hline Hypertension, $n(\%)$ & $163(61)$ & $85(66)$ & $78(55)$ & NS(0.08) \\
\hline Sepsis, $n(\%)$ & $15(5.6)$ & $15(12)$ & $0(0)$ & 0.001 \\
\hline Body temperature $\left({ }^{\circ} \mathrm{C}\right)$ & $36.9 \pm 0.1$ & $37.1 \pm 0.1$ & $36.8 \pm 0.1$ & 0.026 \\
\hline Respiratory rate(/min) & $22 \pm 0$ & $23 \pm 1$ & $21 \pm 0$ & $<0.001$ \\
\hline Mean arterial pressure (mmHg) & $90 \pm 3$ & $92 \pm 7$ & $89 \pm 1$ & NS(0.608) \\
\hline Blood sugar (mg/dl) & $160 \pm 5$ & $166 \pm 9$ & $155 \pm 6$ & $\mathrm{NS}(0.288)$ \\
\hline \multicolumn{5}{|l|}{ AKI biomarkers } \\
\hline Serum IL-18 (ng/ml) & $350 \pm 20$ & $454 \pm 36$ & $256 \pm 15$ & $<0.001$ \\
\hline Urine IL-18 (ng/ml) & $61 \pm 2$ & $64 \pm 3$ & $59 \pm 2$ & NS(0.165) \\
\hline Serum NGAL (ng/ml) & $112 \pm 9$ & $138 \pm 14$ & $88 \pm 10$ & 0.004 \\
\hline Urine NGAL (ng/ml) & $46 \pm 10$ & $77 \pm 20$ & $20 \pm 4$ & 0.007 \\
\hline Serum CysC (mg/L) & $1.9 \pm 0.1$ & $2.4 \pm 0.2$ & $1.5 \pm 0.1$ & 0.001 \\
\hline Urine CysC (mg/L) & $1.0 \pm 0.5$ & $1.8 \pm 1.1$ & $0.4 \pm 0.2$ & $\mathrm{NS}(0.213)$ \\
\hline \multicolumn{5}{|l|}{ Other Laboratory examinations } \\
\hline Serum creatinine baseline (mg/dL) & $1.36 \pm 0.07$ & $1.44 \pm 0.09$ & $1.15 \pm 0.10$ & 0.029 \\
\hline Serum creatinine $0-24 \mathrm{~h}(\mathrm{mg} / \mathrm{dL})$ & $1.64 \pm 0.13$ & $1.96 \pm 0.18$ & $1.07 \pm 0.14$ & $<0.001$ \\
\hline Serum creatinine $24-48 \mathrm{~h}(\mathrm{mg} / \mathrm{dL})$ & $1.50 \pm 0.13$ & $1.81 \pm 0.18$ & $0.93 \pm 0.07$ & $<0.001$ \\
\hline Serum creatinine $48-72 \mathrm{~h}(\mathrm{mg} / \mathrm{dL})$ & $1.49 \pm 0.11$ & $1.79 \pm 0.16$ & $1.02 \pm 0.12$ & $<0.001$ \\
\hline Serum creatinine 7-day (mg/dL) & $1.87 \pm 0.20$ & $1.96 \pm 0.21$ & $0.89 \pm 0.13$ & $<0.001$ \\
\hline Serum creatinine 1-month $(\mathrm{mg} / \mathrm{dL})$ & $1.60 \pm 0.13$ & $1.68 \pm 0.15$ & $1.28 \pm 0.25$ & NS(0.208) \\
\hline Serum creatinine 3-month $(\mathrm{mg} / \mathrm{dL})$ & $1.59 \pm 0.14$ & $1.64 \pm 0.16$ & $1.31 \pm 0.31$ & NS(0.397) \\
\hline Hemoglobin (g/dL) & $12.9 \pm 0.15$ & $12.0 \pm 0.2$ & $13.7 \pm 0.2$ & $<0.001$ \\
\hline Leukocytes $\left(\times 10^{3} / \mu \mathrm{L}\right)$ & $9.5 \pm 0.3$ & $10.0 \pm 0.6$ & $9.1 \pm 0.3$ & NS(0.174) \\
\hline Serum sodium (mmol/L) & $139 \pm 0$ & $139 \pm 0$ & $139 \pm 0$ & NS(0.379) \\
\hline hsCRP (mg/L) & $31 \pm 3$ & $42 \pm 6$ & $20 \pm 3$ & 0.001 \\
\hline Troponin I (ng/ml) & $6.6 \pm 1.0$ & $5.4 \pm 1.2$ & $7.7 \pm 1.7$ & $\mathrm{NS}(0.272)$ \\
\hline BNP (pg/ml) & $725 \pm 70$ & $1025 \pm 106$ & $382 \pm 71$ & $<0.001$ \\
\hline Ejection fraction (\%) & $54 \pm 1$ & $51 \pm 2$ & $57 \pm 1$ & 0.004 \\
\hline Albumin (g/L) & $3.7 \pm 0.0$ & $3.5 \pm 0.1$ & $3.9 \pm 0.0$ & $<0.001$ \\
\hline
\end{tabular}

AKI Acute kidney injury, IL-18 Interleukin 18, NGAL Neutrophil gelatinase-associated lipocalin, CysC Cystatin C, hsCRP High sensitivity C-reactive protein, BNP B-type natriuretic peptide, NS Not significant

significant differences in serum high-sensitive C-reactive protein, B-type natriuretic peptide, albumin and left ventricular ejection fraction measured by echocardiography between the two groups (Table 1). The unit conversion table is provided in Additional file 1: Supplementary Table 1.

Univariate analysis identified that 15 of the 31 variables (Tables 1 and 2) were associated with AKD. Multivariate analysis identified hemoglobin, age, ejection fraction and serum IL-18 as independent predictors of AKD (Table 2). A sensitivity analysis in which patients with CKD were excluded is provided in Additional file 2: Supplementary Table 2.

Goodness-of-fit indices from Hosmer-Lemeshow chi-square analysis were used to assess calibration of the predicted risk of $\mathrm{AKD}$ and the predictive accuracy of serum levels of CysC and IL-18 and both serum and urine levels of NGAL (Table 3). The discriminatory power of these AKI biomarkers are also shown in Table 3. 
Table 2 Logistic regression analysis for AKD according to baseline prognostic factors

\begin{tabular}{|c|c|c|c|c|}
\hline Parameter & $\begin{array}{l}\text { Beta } \\
\text { Coefficient }\end{array}$ & Standard error & Odds ratio $(95 \% \mathrm{Cl})$ & $\boldsymbol{p}$-value \\
\hline \multicolumn{5}{|c|}{ Univariable logistic regression } \\
\hline Age & 0.037 & 0.010 & $1.038(1.018-1.057)$ & $<0.001$ \\
\hline Hemoglobin & -0.321 & 0.059 & $0.725(0.646-0.814)$ & $<0.001$ \\
\hline Body temperature & 0.327 & 0.149 & $1.387(1.036-1.858)$ & 0.028 \\
\hline Respiratory rate & 0.077 & 0.022 & $1.080(1.034-1.128)$ & 0.001 \\
\hline Serum creatinine $0-24 \mathrm{~h}$ & 0.821 & 0.283 & $2.272(1.306-3.954)$ & 0.004 \\
\hline Serum creatinine $24-48 \mathrm{~h}$ & 1.605 & 0.561 & $4.980(1.660-14.940)$ & 0.004 \\
\hline Serum creatinine $48-72 \mathrm{~h}$ & 0.774 & 0.261 & $2.168(1.301-3.614)$ & 0.003 \\
\hline hsCRP & 0.014 & 0.004 & $1.014(1.005-1.023)$ & 0.002 \\
\hline Ejection fraction & -0.022 & 0.008 & $0.978(0.963-0.993)$ & 0.004 \\
\hline BNP & 0.001 & 0.000 & $1.001(1.001-1.002)$ & $<0.001$ \\
\hline Albumin & -1.581 & 0.342 & $0.206(0.105-0.402)$ & $<0.001$ \\
\hline Serum IL-18 & 0.003 & 0.001 & $1.003(1.002-1.005)$ & $<0.001$ \\
\hline Serum NGAL & 0.003 & 0.001 & $1.003(1.001-1.006)$ & 0.009 \\
\hline Urine NGAL & 0.006 & 0.003 & $1.007(1.001-1.012)$ & 0.011 \\
\hline Serum CysC & 0.000 & 0.000 & $1.000(1.000-1.001)$ & 0.001 \\
\hline \multicolumn{5}{|c|}{ Multivariable logistic regression } \\
\hline Hemoglobin & -0.241 & 0.085 & $0.786(0.665-0.928)$ & 0.004 \\
\hline Age & 0.034 & 0.014 & 1.034(1.007-1.063) & 0.014 \\
\hline Ejection fraction & -0.025 & 0.011 & $0.975(0.955-0.996)$ & 0.021 \\
\hline Serum IL-18 & 0.002 & 0.001 & $1.002(1.000-1.004)$ & 0.015 \\
\hline
\end{tabular}

IL-18 Interleukin 18, NGAL Neutrophil gelatinase-associated lipocalin, CysC Cystatin C, hsCRP High sensitivity C-reactive protein, BNP B-type natriuretic peptide

Table 3 Calibration and discrimination of the AKI biomarkers in predicting AKD and 5-year mortality

\begin{tabular}{|c|c|c|c|c|c|c|}
\hline & \multicolumn{3}{|l|}{ Calibration } & \multicolumn{3}{|l|}{ Discrimination } \\
\hline & Goodness -of-fit (x2) & $\mathrm{df}$ & $p$-value & $\overline{A U R O C} \pm S E$ & $95 \% \mathrm{Cl}$ & $p$-value \\
\hline \multicolumn{7}{|c|}{ For $A K D$ prediction } \\
\hline Serum IL-18 & 10.518 & 8 & 0.231 & $0.698 \pm 0.033$ & $0.634-0.762$ & $<0.001$ \\
\hline Serum NGAL & 5.756 & 8 & 0.675 & $0.630 \pm 0.034$ & $0.563-0.697$ & $<0.001$ \\
\hline Urine NGAL & 12.980 & 8 & 0.113 & $0.660 \pm 0.036$ & $0.591-0.730$ & $<0.001$ \\
\hline Serum CysC & 9.448 & 8 & 0.306 & $0.663 \pm 0.033$ & $0.598-0.728$ & $<0.001$ \\
\hline \multicolumn{7}{|c|}{ For 5-year mortality prediction } \\
\hline Serum IL-18 & 0.712 & 8 & 0.999 & $0.522 \pm 0.048$ & $0.429-0.616$ & 0.635 \\
\hline Serum NGAL & 9.717 & 8 & 0.285 & $0.573 \pm 0.047$ & $0.482-0.665$ & 0.113 \\
\hline Urine NGAL & 19.266 & 8 & 0.014 & $0.712 \pm 0.047$ & $0.620-0.803$ & $<0.001$ \\
\hline Serum CysC & 7.780 & 8 & 0.455 & $0.554 \pm 0.048$ & $0.460-0.648$ & 0.241 \\
\hline
\end{tabular}

No statistically significant AUROC differences between serum IL-18, serum NGAL, urine NGAL and serum CysC for AKD prediction*.

Statistically significant AUROC differences between urine NGAL vs. serum IL-18, serum NGAL and serum CysC for 5 -year mortality prediction, all $p$-values $<0.01 *$ AKI Acute kidney injury, AKD Acute kidney disease, IL-18 Interleukin 18, NGAL Neutrophil gelatinase-associated lipocalin, CysC Cystatin C, AUROC Area under the receiver operating characteristic curve

*Pairwise comparisons of ROC curves, by Delong method, 1988 
Five-year all-cause mortality of the AKD patients and AKI biomarkers

Cox proportional hazard analysis identified 11 variables with prognostic value for 5-year all-cause mortality (Table 4). Multiple Cox regression analysis showed that urine NGAL, body weight and hemoglobin on first day of CCU admission were independent risk factors for 5year all-cause mortality.

The 5-year all-cause mortality rates were $14.2 \%$ (20/ 141 ) for the non-AKD group, $10.2 \%(5 / 49)$ for AKD stage $0 \mathrm{~A}, 17.3 \%(9 / 52)$ for AKD stage $0 \mathrm{C}, 41.7 \%(5 / 12)$ for AKD stage $1,62.5 \%$ (5/8) for AKD stage 2, and $71.4 \%$ (5/7) for AKD stage 3 (chi-square for trend; $p<$ 0.001 ). The odds ratios for AKD stage were 0.688 for AKD stage $0 \mathrm{~A}$ versus non-AKD $(p=0.480), 1.266$ for stage $0 \mathrm{C}$ versus non-AKD $(p=0.591), 4.321$ for stage 1 versus non-AKD $(p=0.021), 10.083$ for stage 2 versus non-AKD $(p=0.003)$, and 15.125 for stage 3 versus nonAKD $(p=0.002)$ (Table 5). Cumulative survival rates differed significantly $(p<0.005)$ between group 1 (non-AKI or AKD, AKD stage $0 \mathrm{~A}$ and $0 \mathrm{C}$ ) and group 2 (AKD stage 1, 2 and 3) (Fig. 3). In addition, the 5-year survival rates also differed significantly between the fourth quarter of urine NGAL (Q4: $>25.66 \mathrm{ng} / \mathrm{ml}$ ) and the other three quarters (Q1: < $4.14 \mathrm{ng} / \mathrm{ml} ; \mathrm{Q} 2: 4.14-9.67 \mathrm{ng} / \mathrm{ml}$; and Q3: 9.67-25.66 ng/ml) (Fig. 4).

\section{Discussion}

The consensus report of the ADQI 16 Workgroup proposed the term AKD to define the pathway of renal pathophysiological processes that are continuing after
AKI [1]. In this study, we found that clinical and laboratory variables (including AKI biomarkers) obtained during the first day of CCU admission were of predictive value for future AKD. Most CCU patients are diagnosed with coronary artery disease and related acute myocardial infarction. Peri-coronary artery catheterizationrelated contrast-associated AKI, post-acute myocardial infarction decompensated heart failure, hypoxemic respiratory failure and preexisting CKD have all been reported to contribute to the deterioration of renal function and to increase in-hospital mortality $[17,18]$. In addition, ongoing heart failure, factors related to prolonged renal recovery (age, underlying diseases such as diabetes mellitus or hypertension, CKD or not, chronic medication usage) and intrinsic renal parenchymal injury are all related to the development of future AKD.

Previous studies have reported that AKI biomarkers including CysC, IL-18 and NGAL can improve the diagnosis of intrinsic AKI in CCU patients $[9,10]$. In this study, we identified that age, ejection fraction, levels of hemoglobin and serum IL-18 were independent predictors of AKD in our CCU patients. Type 1 CRS indicates acute cardiac dysfunction leading to acute kidney dysfunction [19]. The proposed mechanisms include decreased cardiac output and renal perfusion pressure, venous congestion, neurohormonal dysregulation and systemic inflammation. Decreased ejection fraction reflects decreased cardiac output and renal hypoperfusion, which in turn causes functional AKI and parenchymal damage. Delayed improvement in renal function and prolonged renal parenchymal injury may lead to AKD.

Table 4 Cox regression analysis for all-cause 5-year mortality

\begin{tabular}{|c|c|c|c|c|}
\hline Parameter & Beta coefficient & Standard error & Hazard ratio $(95 \% \mathrm{Cl})$ & $p$-value \\
\hline \multicolumn{5}{|c|}{ Univariate hazard analysis } \\
\hline Hemoglobin & -0.207 & 0.057 & $0.813(0.726-0.909)$ & $<0.001$ \\
\hline Age & 0.023 & 0.011 & $1.024(1.001-1.046)$ & 0.037 \\
\hline Gender, Male & -0.705 & 0.300 & $0.494(0.274-0.890)$ & 0.019 \\
\hline Body weight & -0.044 & 0.014 & $0.957(0.932-0.983)$ & 0.001 \\
\hline Serum CysC & 0.000 & 0.000 & $1.000(1.000-1.000)$ & 0.015 \\
\hline Urine NGAL & 0.002 & 0.001 & $1.002(1.001-1.003)$ & 0.001 \\
\hline Urine CysC & 0.000 & 0.000 & $1.000(1.000-1.000)$ & $<0.001$ \\
\hline hsCRP & 0.006 & 0.003 & $1.006(1.001-1.011)$ & 0.029 \\
\hline Albumin & -1.046 & 0.261 & $0.351(0.211-0.586)$ & $<0.001$ \\
\hline Serum sodium & -0.117 & 0.042 & $0.890(0.820-0.966)$ & 0.005 \\
\hline BNP & 0.001 & 0.000 & $1.001(1.000-1.001)$ & $<0.001$ \\
\hline \multicolumn{5}{|c|}{ Multivariate hazard analysis } \\
\hline Urine NGAL & 0.003 & 0.001 & $1.003(1.001-1.005)$ & 0.006 \\
\hline Body weight & -0.040 & 0.018 & $0.961(0.927-0.996)$ & 0.03 \\
\hline Hemoglobin & -0.268 & 0.104 & $0.765(0.625-0.937)$ & 0.01 \\
\hline
\end{tabular}

NGAL Neutrophil gelatinase-associated lipocalin, CysC Cystatin C, hsCRP High sensitivity C-reactive protein, BNP B-type natriuretic peptide 
Table 5 AKD stages and 5-year all-cause-mortality

\begin{tabular}{lllllll}
\hline AKD stage & $\mathrm{n}$ & 5 -year all-cause-mortality (\%) & Beta-coefficient & Standard error & Odds ratio, 95\% Cl & $\boldsymbol{p}$-value \\
\hline Non-AKD & 141 & 14.2 & - & - & 1 (reference) & - \\
OA & 49 & 10.2 & -0.375 & 0.530 & $0.688(0.243-1.943)$ & NS (0.480) \\
OC & 52 & 17.3 & 0.236 & 0.439 & $1.266(0.536-2.993)$ & NS (0.591) \\
1 & 12 & 41.7 & 1.464 & 0.633 & $4.321(1.249-14.953)$ & 0.021 \\
2 & 8 & 62.5 & 2.311 & 0.769 & $10.083(2.233-45.531)$ & 0.003 \\
3 & 7 & 71.4 & 2.716 & 0.871 & $15.125(2.745-83.350)$ & 0.002
\end{tabular}

AKD Acute kidney disease

Previous studies have reported associations between serum IL-18 and a diagnosis of AKI, cardiac and renal outcomes. Striz et al. reported a higher level of serum IL-18 in patients with acute renal allograft rejection compared to those with an uncomplicated transplantation, and also that IL-18 mRNA was released in response to increased IFN- $\gamma$ and TNF- $\alpha$ production [20]. In addition, a Japanese study reported that serum IL-18 was correlated with carotid intima-media thickness and urinary albumin excretion in diabetic nephropathy patients [21]. Therefore, serum IL-18 level may be a predictor of both cardiovascular diseases and renal outcome in patients with type 2 diabetes mellitus. Moreover, a study of middle-aged Europeans also reported that serum IL-18 level was an independent predictor of coronary events [22]. Furthermore, IL-18 genetic variations have been reported to influence the serum levels of IL18 and the clinical outcomes of patients with coronary artery disease [23]. In the present study, the higher level of serum IL-18 may reflect more severe renal parenchymal injury, meaning more extensive tissue damage which may have prolonged the recovery time from AKI. AKD is diagnosed when serum creatinine fails to return to baseline or there is biomarker evidence of decreased renal reserve after 7 days.

The levels of AKI biomarkers have been reported to be independent predictors of short-term and long-term mortality $[9,24]$. Urine NGAL has been shown to predict renal outcomes (kidney intrinsic injury, AKI progression, renal replacement therapy) and clinical outcomes in children undergoing cardiac surgery, critically ill intensive care unit patients, septic AKI patients and patients who visited emergency rooms [4, 25-28]. In addition, urine NGAL was shown to predict 28-day mortality in 109 intensive care unit patients in a study by Kümpers et al. [29]. However, very few studies have investigated associations between AKI biomarkers and long-term clinical prognosis. In the present study, we demonstrated that urine NGAL could independently predict 5-year mortality in our CCU patients, especially when the urine NGAL level exceeded $25.66 \mathrm{ng} / \mathrm{ml}$.

In addition, anemia is a known predictor of rehospitalization and mortality in patients with congestive heart failure [30, 31]. Cardiac renal anemia syndrome, characterized by concomitant cardiorenal dysfunction and anemia, highlights the importance of anemia in these patients [32]. The presence of anemia can increase the impact of cardiac or renal dysfunction on morbidity and mortality. The SENIOR study reported that the 309 included anemic patients (10\%) were older and had poorer renal function $(p<0.05)$ compared to those without anemia. In addition, anemia has been reported to be an independent risk factor for all-cause mortality and hospitalization for cardiovascular disease [33]. In the present study, we demonstrated that body weight and hemoglobin and urine NGAL levels were independently associated with the risk of all-cause 5-year mortality in our CCU patients, which is consistent with previously published studies.

Furthermore, we observed that a higher AKD stage was correlated with higher 5-year all-cause mortality (patients with AKD stage 3 had a 15 -fold higher risk of mortality compared to those without AKD). To the best of our knowledge, this is the first study to report an association between the severity of AKD and 5-year clinical outcomes in $\mathrm{CCU}$ patients. Interestingly, we observed that the 5-year cumulative survival rate of the patients diagnosed with AKD stage 0A (normalized creatinine level post-AKI) was slightly higher than in the patients without AKI and in those with AKD alone, despite being statistically insignificant. A previous metaanalysis demonstrated that patients who were referred to a nephrologist earlier had reduced mortality and complications of CKD [34]. We advised most of our patients who presented with AKD to receive follow-up with a nephrologist after being discharged from the CCU to monitor their health condition, including important risk factors. This kind of surveillance may help to lower the 5 -year mortality rate of patients with AKD stage 0A.

\section{Study limitations}

There are several limitations to the present study. First, it was conducted at one single center, and most of the patients were of East Asian ethnicity. Therefore, extrapolation of our results to other patient groups needs to be validated. Second, this study involved prospective data 


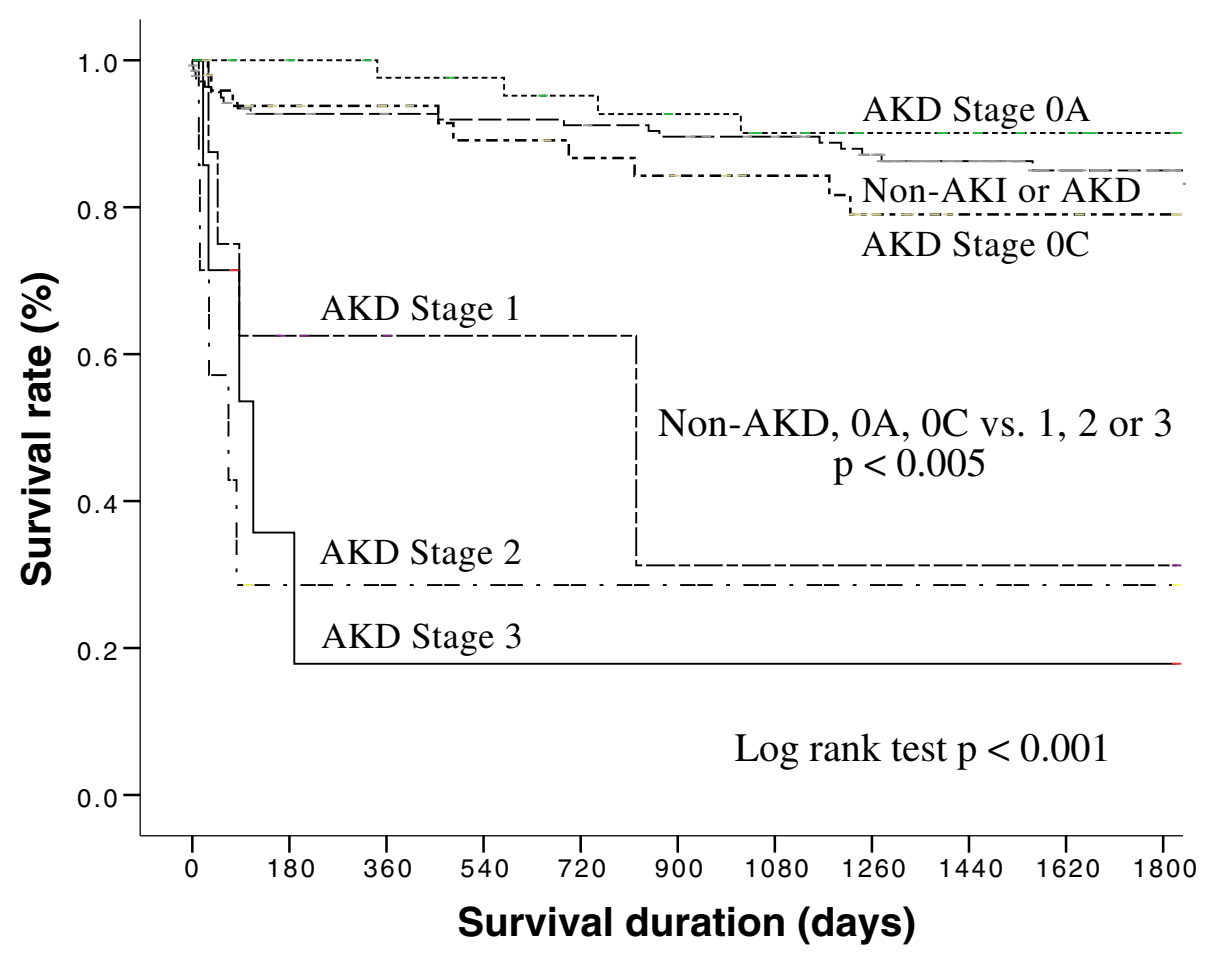

Fig. 3 Cumulative survival rates for the 269 patients by stage of AKD. AKD, acute kidney disease; CCU, coronary care unit

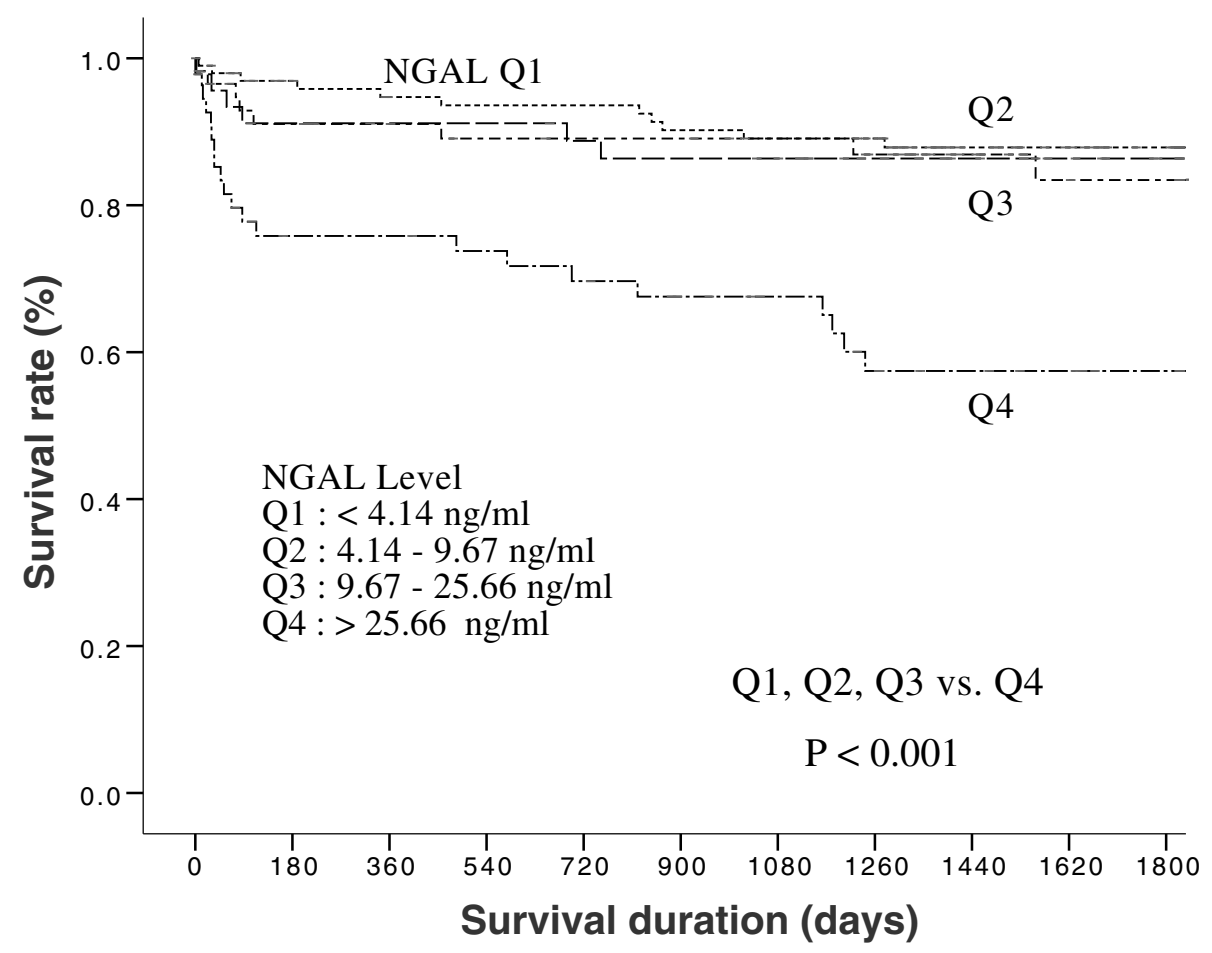

Fig. 4 Cumulative survival rates for the 269 patients by urine NGAL quartile on the first day of CCU admission. AKD, acute kidney disease; CCU, coronary care unit; NGAL, neutrophil gelatinase-associated lipocalin 
collection and post hoc analysis, so AKI biomarker data (including IL-18, serum and urine $\mathrm{CysC}$ ) during the observation interval of AKD (i.e., 7 days to 3 months) were lacking, and therefore we could not accurately define the number of patients with AKD stage 0B. Third, only single measurements of AKI biomarkers were collected, so we could not observe continuous time-course changes in the AKI biomarkers. Fourth, there are inherent limitations with regards to the predictive accuracy of logistic regression analysis. Fifth, uric acid levels were not measured, and so we could not investigate whether hyperuricemia contributes to AKI and AKD, or whether it is simply a consequence of a decline in glomerular filtration rate and relative hypovolemia. Sixth, communityacquired AKI may have been mis-diagnosed as CKD as we used first serum creatinine data during admission, and the true incidence of AKI may have been underestimated. Finally, considering the intensive care unit setting and observational design, further prospective randomized controlled trials are necessary to validate the costefficacy of using AKI biomarkers to improve clinical outcomes.

\section{Conclusions}

In conclusion, this investigation confirmed that AKI biomarkers can be used to predict AKD in CCU patients. Age, ejection fraction, hemoglobin and serum IL-18 were independently associated with the $\mathrm{CCU}$ patients who developed AKD. In addition, body weight, hemoglobin and urine NGAL could predict 5-year survival in the patients who were admitted to the CCU and diagnosed with AKD.

\section{Supplementary information}

Supplementary information accompanies this paper at https://doi.org/10. 1186/s12882-020-01872-z.

Additional file 1 Supplementary Table 1. The unit conversion table. Additional file $\mathbf{2}$ Supplementary Table $\mathbf{2}$. Logistic regression analysis for AKD according to baseline prognostic factors after excluding patients with CKD.

\section{Abbreviations \\ ADQI: Acute Disease Quality Initiative; AKI: Acute kidney injury; AKD: Acute kidney disease; CCU: Coronary care unit; CKD: Chronic kidney disease: CRS: Cardio-renal syndrome; IL-18: Interleukin 18; NGAL: Neutrophil gelatinase-associated lipocalin; CysC: Cystatin C}

\section{Acknowledgements}

Not applicable.

\section{Authors' contributions}

YTC contributed to writing the article and constructing tables and figures CCJ revised and checked the article. $\mathrm{CCH}$ collected and analyzed original data. PCF contributed to data collection and revised the article. HCP provided study direction and revised the article. WIW, WJC, YCY, and $\mathrm{CKH}$ contributed to data collection and constructing tables and Figs. YCC provided original idea, analyzed data and supervised this study. All authors approved the final version of the manuscript.

\section{Funding}

This work was supported by the Ministry of Science and Technology of Taiwan (MOST107-2314-B-182A-019-MY3) and in part by the Chang Gung Medical Research Fund (CLRPG2H0041). Quantifying of serum and urinary acute kidney injury biomarkers were funded in this study. No funders had a role in the design of the study, data collection, analysis and data interpretation, or writing of the manuscript.

\section{Availability of data and materials}

The datasets generated and/or analyzed during the current study are not publicly available due the specification of the Institutional Review Board at Chang Gung Memorial Hospital but are available from the corresponding author on reasonable request.

\section{Ethics approval and consent to participate}

The Institutional Review Board at Chang Gung Memorial Hospital approved the study protocol (approval No. 201702274B0). All patients provided written informed consent to join the study.

\section{Consent for publication}

Not applicable.

\section{Competing interests}

The authors declare that they have no competing interests.

\section{Author details}

${ }^{1}$ Department of Nephrology, Chang Gung Memorial Hospital, Keelung, Taiwan. ${ }^{2}$ Kidney Research Center, Department of Nephrology, Chang Gung Memorial Hospital, Linkou, Taiwan. ${ }^{3}$ Department of Neurology, Chang Gung Memorial Hospital, Keelung, Taiwan. ${ }^{4}$ College of Medicine, Chang Gung University, Taoyuan, Taiwan. ${ }^{5}$ Department of Cardiology, Chang Gung Memorial Hospital, Linkou, Taiwan. ${ }^{6}$ Community Medicine Research Center, Chang Gung Memorial Hospital, Keelung, Taiwan. ${ }^{7}$ Division of Nephrology, Department of Medicine, Keelung Chang Gung Memorial Hospital, No. 222, Maijin Rd., Anle Dist, Keelung City, Taiwan.

Received: 21 December 2018 Accepted: 25 May 2020

Published online: 01 June 2020

\section{References}

1. Chawla LS, Bellomo R, Bihorac A, Goldstein SL, Siew ED, Bagshaw SM, Bittleman D, Cruz D, Endre Z, Fitzgerald RL, et al. Acute kidney disease and renal recovery: consensus report of the acute disease quality initiative (ADQI) 16 workgroup. Nat Rev Nephrol. 2017;13(4):241-57.

2. Chou YH, Huang TM, Chu TS. Novel insights into acute kidney injury-chronic kidney disease continuum and the role of renin-angiotensin system. J Formos Med Assoc. 2017;116(9):652-9.

3. Chawla LS, Eggers PW, Star RA, Kimmel PL. Acute kidney injury and chronic kidney disease as interconnected syndromes. N Engl J Med. 2014;371(1):5866.

4. Bagshaw SM, Uchino S, Bellomo R, Morimatsu H, Morgera S, Schetz M, Tan I, Bouman C, Macedo E, Gibney N, et al. Septic acute kidney injury in critically ill patients: clinical characteristics and outcomes. Clin J Am Soc Nephrol. 2007:2(3):431-9.

5. Hoste EAJ, Bagshaw SM, Bellomo R, Cely CM, Colman R, Cruz DN, Edipidis K, Forni LG, Gomersall CD, Govil D, et al. Epidemiology of acute kidney injury in critically ill patients: the multinational AKI-EPI study. Intensive Care Med. 2015:41(8):1411-23.

6. Karvellas CJ, Farhat MR, Sajjad I, Mogensen SS, Leung AA, Wald R, Bagshaw SM. A comparison of early versus late initiation of renal replacement therapy in critically ill patients with acute kidney injury: a systematic review and meta-analysis. Crit Care. 2011;15(1):R72.

7. Chertow GM, Burdick E, Honour M, Bonventre JV, Bates DW. Acute kidney injury, mortality, length of stay, and costs in hospitalized patients. J Am Soc Nephrol. 2005;16(11):3365-70.

8. Ronco C, Haapio M, House AA, Anavekar N, Bellomo R. Cardiorenal syndrome. J Am Coll Cardiol. 2008;52(19):1527-39.

9. Chen $\mathrm{TH}$, Chang $\mathrm{CH}$, Lin CY, Jenq CC, Chang MY, Tian YC, Hung CC, Fang JT, Yang CW, Wen MS, et al. Acute kidney injury biomarkers for patients in a coronary care unit: a prospective cohort study. PLoS One. 2012;7(2):e32328. 
10. Chang $\mathrm{CH}$, Yang $\mathrm{CH}$, Yang HY, Chen $\mathrm{TH}$, Lin CY, Chang SW, Chen YT, Hung CC, Fang JT, Yang CW, et al. Urinary biomarkers improve the diagnosis of intrinsic acute kidney injury in coronary care units. Medicine (Baltimore). 2015;94(40):e1703.

11. Parikh CR, Mishra J, Thiessen-Philbrook H, Dursun B, Ma Q, Kelly C, Dent C, Devarajan P, Edelstein CL. Urinary IL-18 is an early predictive biomarker of acute kidney injury after cardiac surgery. Kidney Int. 2006;70(1):199-203.

12. Thygesen K, Alpert JS, Jaffe AS, Simoons ML, Chaitman BR, White HD. Third universal definition of myocardial infarction. Glob Heart. 2012;7(4):275-95.

13. Ho KK, Anderson KM, Kannel WB, Grossman W, Levy D. Survival after the onset of congestive heart failure in Framingham heart study subjects. Circulation. 1993;88(1):107-15.

14. Bone RC, Balk RA, Cerra FB, Dellinger RP, Fein AM, Knaus WA, Schein RMH, Sibbald WJ. Definitions for Sepsis and organ failure and guidelines for the use of innovative therapies in Sepsis. CHEST. 1992;101(6):1644-55.

15. Kellum JA, Lameire N, Aspelin P, Barsoum RS, Burdmann EA, Goldstein SL, Herzog CA, Joannidis M, Kribben A, Levey AS. Kidney disease: improving global outcomes (KDIGO) acute kidney injury work group. KDIGO clinical practice guideline for acute kidney injury. Kidney Int Suppl. 2012;2(1):1-138.

16. Ma YC. Modified glomerular filtration rate estimating equation for Chinese patients with chronic kidney disease. J Am Soc Nephrol. 2006;17(10):2937-44.

17. Marenzi G, Lauri G, Assanelli E, Campodonico J, De Metrio M, Marana I, Grazi M, Veglia F, Bartorelli AL. Contrast-induced nephropathy in patients undergoing primary angioplasty for acute myocardial infarction. J Am Coll Cardiol. 2004;44(9):1780-5.

18. Wright R, Reeder GS, Herzog CA, et al. Acute myocardial infarction and renal dysfunction: a high-risk combination. Ann Intern Med. 2002;137(7):563-70.

19. Ronco C, Cicoira M, McCullough PA. Cardiorenal syndrome type 1. J Am Coll Cardiol. 2012;60(12):1031-42.

20. Striz I, Krasna E, Honsova E, Lacha J, Petrickova K, Jaresova M, Lodererova A, Bohmova R, Valhova S, Slavcev A, et al. Interleukin 18 (IL-18) upregulation in acute rejection of kidney allograft. Immunol Lett. 2005;99(1):30-5.

21. Nakamura A, Shikata K, Hiramatsu M, Nakatou T, Kitamura T, Wada J, Itoshima T, Makino H. Serum Interleukin-18 levels are associated with nephropathy and atherosclerosis in Japanese patients with type 2 diabetes. Diabetes Care. 2005;28(12):2890.

22. Blankenberg S, Luc G, Ducimetiere P, Arveiler D, Ferrieres J, Amouyel P, Evans A, Cambien F, Tiret L, Group PS. Interleukin-18 and the risk of coronary heart disease in European men: the prospective epidemiological study of myocardial infarction (PRIME). Circulation. 2003;108(20):2453-9.

23. Tiret L, Godefroy T, Lubos E, Nicaud V, Tregouet D-A, Barbaux S, Schnabel R, Bickel C, Espinola-Klein C, Poirier O, et al. Genetic analysis of the interleukin18 system highlights the role of the interleukin-18 gene in cardiovascular disease. Circulation. 2005;112(5):643-50.

24. Coca SG, Garg AX, Thiessen-Philbrook H, Koyner JL, Patel UD, Krumholz HM, Shlipak MG, Parikh CR, Consortium T-A. Urinary biomarkers of AKI and mortality 3 years after cardiac surgery. J Am Soc Nephrol. 2014;25(5):1063-71.

25. Cruz DN, de Cal M, Garzotto F, Perazella MA, Lentini P, Corradi V, Piccinni P, Ronco C. Plasma neutrophil gelatinase-associated lipocalin is an early biomarker for acute kidney injury in an adult ICU population. Intensive Care Med. 2010:36(3):444-51.

26. Nickolas TL, O'Rourke MJ, Yang J, et al. SEnsitivity and specificity of a single emergency department measurement of urinary neutrophil gelatinaseassociated lipocalin for diagnosing acute kidney injury. Ann Intern Med. 2008;148(11):810-9.

27. Siew ED, Ware LB, Gebretsadik T, Shintani A, Moons KGM, Wickersham N, Bossert F, Ikizler TA. Urine neutrophil Gelatinase-associated Lipocalin moderately predicts acute kidney injury in critically ill adults. J Am Soc Nephrol. 2009:20(8):1823-32.

28. Bennett M, Dent CL, Ma Q, Dastrala S, Grenier F, Workman R, Syed H, Ali S, Barasch J, Devarajan P. Urine NGAL predicts severity of acute kidney injury after cardiac surgery: a prospective study. Clin J Am Soc Nephrol. 2008;3(3):665-73.

29. Kümpers $P$, Hafer $C$, Lukasz A, Lichtinghagen $R$, Brand $K$, Fliser D, FaulhaberWalter R, Kielstein JT. Serum neutrophil gelatinase-associated lipocalin at inception of renal replacement therapy predicts survival in critically ill patients with acute kidney injury. Crit Care. 2010;14(1):R9.

30. Belziti CA. Prevalence of anemia in heart failure and its effects on prognosis. Expert Rev Cardiovasc Ther. 2009;7(2):131-8.

31. Terrovitis JV, Anastasiou-Nana M, Kaldara E, Drakos SG, Nanas SN, Nanas JN. Anemia in heart failure: pathophysiologic insights and treatment options. Futur Cardiol. 2008;5(1):71-81.
32. Efstratiadis G, Konstantinou D, Chytas I, Vergoulas G. Cardio-renal anemia syndrome. Hippokratia. 2008;12(1):11-6.

33. von Haehling $S$, van Veldhuisen DJ, Roughton $M$, Babalis D, de Boer RA, Coats AJ, Manzano L, Flather M, Anker SD. Anaemia among patients with heart failure and preserved or reduced ejection fraction: results from the SENIORS study. Eur J Heart Fail. 2011;13(6):656-63.

34. Smart NA, Titus T. Outcomes of Early versus Late Nephrology Referral in Chronic Kidney Disease: A Systematic Review. Am J Med. 2011;124(11): 1073-1080.e1072.

\section{Publisher's Note}

Springer Nature remains neutral with regard to jurisdictional claims in published maps and institutional affiliations.
Ready to submit your research? Choose BMC and benefit from:

- fast, convenient online submission

- thorough peer review by experienced researchers in your field

- rapid publication on acceptance

- support for research data, including large and complex data types

- gold Open Access which fosters wider collaboration and increased citations

- maximum visibility for your research: over $100 \mathrm{M}$ website views per year

At BMC, research is always in progress.

Learn more biomedcentral.com/submissions 